\title{
Management Issues of Budd Chiari Syndrome and Portal Hypertension in Pregnancy
}

\author{
Ripal Gevariya ${ }^{1 *}$ and Pathik Parikh ${ }^{2}$ \\ Paras Maternity Care, Ahmedabad, India \\ Apollo Hospitals, Mumbai, India
}

Submission: April 05, 2017 ; Published: May 02, 2017

*Corresponding author: Ripal Gevariya, Paras Maternity Care, Ahmedabad, India, Email:ripal179@gmail.com

\section{Review}

Biochemical changes are common during pregnancy. Although not very common, liver diseases do occur during pregnancy. Three to five percent of pregnancies are complicated by liver diseases. Jaundice is reported 1 in 1500 to 1 in 5000 pregnancies [1]. The most common reason is viral hepatitis $(42 \%)$ while the second most common reason is one that is caused by pregnancy-specific disease, intrahepatic cholestasis (20\%). On the other hand, the most common cause of altered liver enzymes in pregnancy is toxaemia of pregnancy related $(70 \%)$, though complete HELLP syndrome is much less common (4\%). Sepsis, particularly UTI should be considered as a differential diagnosis of raised liver enzymes [1]. The diagnosis of liver disease in pregnancy is challenging as signs and symptoms are often not specific and consist of anorexia, nausea, vomiting, and abdominal pain, with jaundice often being absent, or noticed as mild. The underlying disorder can have a significant effect on morbidity and mortality in both mother and fetus.

Pregnancy is a physiological hypercoagulable state. The hypercoagulable state increases during puerperium even further. The risk of venous thromboembolism is 10 times more as compared to non-pregnant women [2], while in puerperium the risk is 60 times compared to non-preganant [3]. Budd-Chiari syndrome is a rare and potentially life-threatening disorder characterised by obstruction of the hepatic outflow tract at any level between the junction of the inferior vena cava with the right atrium and the main hepatic veins. In a recently published meta-analysis, the prevalence of pregnancy-related Budd-Chiari syndrome has varied from 0 to 21.5\%. [4]. In Asian countries, prolonged rest postpartum is followed by late and slow mobilisation after childbirth. In the study by Dilawari et al. [5] in rural India, puerperal women often experience up to 30 or 40 days of confinement and fluid restriction. Thus, the combination of increased clotting factors, lack of activity, and dehydration on a background of thrombophilic state may constitute a condition conducive to venous thrombotic complications, potentiallyleading to a higher prevalence of pregnancy-related BCS in Indian studies (13.1\%). Common thrombophilic factors include inherited and acquired thrombophilia, such as antithrombin deficiency, protein $\mathrm{C}$ deficiency, protein S deficiency, heterozygous Factor V Leiden, prothrombin G20210A mutation, homozygous MTHFR mutation and hyperhomocysteinemia, and myeloproliferativeneoplasms. BCS entails thrombosis of the hepatic vein resulting in passive congestion of the hepatic sinusoids leading to ischemia and portal hypertension. Over a period of time, if untreated it can lead to cirrhosis of liver because of ongoing sinusoidal hemorrhage and fibrosis. Clinical manifestations can be diverse, making BCS a possible differential diagnosis of many acute and chronic liver diseases. There is the development of abdominal pain, ascites, hepatomegaly,(classic triad), pedal oedema, splenomegaly and varices. However, occasionally it may lead to acute liver failure with encephalopathy and coagulopathy when the hepatic veins get thrombosed acutely [6]. The treatment is anticoagulation at the earliest and attempt to cannulate the hepatic veins and put a hepatic vein metallic stent. In case if it is not technically possible, TIPS is an option [7]. In the case of acute liver failure, liver transplant remains the treatment of choice (6). Even after the therapeutic radiological or surgical procedures, the present guidelines recommend lifelong anticoagulation for Budd-Chiari syndrome [8].

\section{Anticoagulation in Pregnancy}

Parenteral anticoagulants inactivate thrombin and/or factor Xa without depleting circulating levels of clotting factors [9]. Unfractionated heparin (UFH), low-molecular weight heparin (LMWH), heparinoids, synthetic pentasaccharide inhibitors (eg, fondaparinux), and direct thrombin inhibitors (ie, hirudin and argatroban) belong to this category. LMWH is preferred over UFH owing to its ease of use, as well as it greater efficacy and safety profile though no randomised study has been done 
[10]. If possible, warfarin therapy should be avoided during pregnancy [11] If warfarin therapy is essential, it should be avoided at least during the first trimester (because of teratogenicity) and from about 2 to 4 weeks before delivery to reduce the risk of hemorrhagic complications. The safety and efficacy of rivaroxaban or dabigatran in pregnancy have not been established.

\section{Transjugular Intrahepatic Portosystemics Hunts in Pregnancy}

Transjugular Intrahepatic Portosystemic Shunt or TIPS is a radiological procedure in which an expandable metallic stent is put between the branch of the portal vein and hepatic vein. This bypasses the sinusoids and can relieve portal hypertension. It has been an established treatment for refractory variceal bleed and refractory as cites. However, in the last decade, it has also become a standard treatment option in Budd-Chiari syndrome to bypass the obstruction when a direct hepatic vein stent in the obstructed hepatic vein could not be placed or have failed. However, it entails significant radiation. TIPS during pregnancy have been used for life-threatening conditions like variceal bleed in the past [12] However, there is not enough evidence for its use in Budd-Chiari syndrome in pregnancy. A recent case series from the US, though have documented its safety [13].

Chronic Liver Disease and Portal Hypertension in Pregnancy

It is uncommon for patients with cirrhosis to become pregnant. Portal hypertension could be due to underlying cirrhosis or even non-cirrhotic portal hypertension. Portal hypertension is an important issue in pregnancy as it increases the risk of hepatic de compensation, variceal haemorrhage, splenic artery aneurysm, uterine haemorrhage and an overall increase in mortality. In a study published by Abdel Aziz M [14] which included 339 cirrhotic women, maternal mortality was $1.8 \%$ and fetal mortality was $5.2 \%$ overall. Gestational hypertension, placental abruption and uterovaginal haemorrhage were more common in patients with cirrhosis; their infants had higher rates of prematurity and growth restriction. Hepatic de compensation occurred in $15 \%$, including as cites in $11 \%$ and variceal haemorrhage in $5 \%$. In women with de compensation, maternal and fetal mortality were 6 and $12 \%$ respectively. The risk of caesarian section was higher with an odds ratio of 1.41 .

As cites is not very common in pregnancy as raised intra abdominal pressure prevents extravasation from splanchnic vessels. But if as cites does occur, the treatment remains the same as in non-pregnant patients. Patients are to be started on diuretics and salt restriction. Both the commonly used diuretics, Frusemide and Spironolactone are FDA category C drugs. Similarly, hepatic encephalopathy can be treated as in non-pregnant women with lactulose/lactitol (Category B) and rifaximin (Category C). Splenic artery aneurysm may occur in patients with portal hypertension with effects of oestrogen.
The treatment in case of rupture is emergent radiological embolization or graft placement.

Oesophagal variceal bleeding has been reported in $18 \%$ to $32 \%$ of pregnant women with cirrhosis and in up to $50 \%$ of those with known portal hypertension $[15,16]$. Among those with preexisting varices, up to $78 \%$ will have gastrointestinal bleeding during pregnancy, with a mortality rate between $2 \%$ to $6 \%$ due to bleeding [17]. Variceal bleeding most commonly occurs during the second and third trimesters when maternal blood volume is maximally expanded and the larger fetus causes increased compression of the inferior vena cava and collateral vasculature. Endoscopic variceal ligation (EVL) remains the mainstay of treatment. Band ligation should be preferred during pregnancy because sclerosant therapy is considered to have higher complications rate and required a greater number of sessions. Octreotide is a category B drug and may be used for acute variceal bleed. Terlipressin/somatostatin is avoided as it increases the foetal complications. TIPS have been tried and reported in previous studies to be effective and the radiation dose was believed to be safe [13]. Non-selective beta blockers are category $\mathrm{C}$ and in patients with a history of variceal bleed, the benefits outweigh the risks for its use [18]. The risk of variceal bleeding is increased at the time of delivery because of the need for repetitive Valsalvamanoeuvre. No randomised controlled trials have been performed to support prophylactic caesarian section in these patients though it has been suggested by few experts. A special effort should be made to shorten the second stage of labour by assisted delivery and to decrease the straining as it may precipitate variceal bleed. The caesarian section is justified only for obstetric indications.

To conclude Pregnancy is a hyper coagulable state and symptoms of abdominal pain and pedal oedema, although nonspecific, should not be ignored. Ultrasound with doppler should be carried out for all patients with as cites. Anticoagulation and diuretics can be administered in pregnant women considering the risk-benefit ratio. Liver specialist opinion should be sought at the earliest for early diagnosis and management as a delay may be associated with maternal and fetal morbidity and mortality. Radiological interventions may be offered to the patient with Budd-Chiari syndrome when benefits outweigh the risk of radiation exposure.

\section{References}

1. Chng CL, Morgan M, Hainsworth I, Kingham JG (2002) Prospective study of liver dysfunction in pregnancy in Southwest Wales. Gut 51(6): 876-880.

2. Ray JG, Chan WS (1999) Deep vein thrombosis during pregnancy and the puerperium: a meta-analysis of the period of risk and the leg of presentation. Obstetrical and Gynecological Survey 54(4): 265-271.

3. Mahmoodi BK, Brouwer JLP, Ten Kate MK (2010) A prospective cohort study on the absolute risks of venous thromboembolism and predictive value of screening asymptomatic relatives of patients with hereditary deficiencies of protein $\mathrm{S}$, protein $\mathrm{C}$ or antithrombin. Journal of Thrombosis and Haemostasis 8(6): 1193-1200. 
4. Ren W, Li X, Jia J, Xia Y, Hu F, et al. (2015) Prevalence of Budd-Chiari Syndrome during Pregnancy or Puerperium: A Systematic Review and Meta-Analysis. Gastroenterol Res Pract 2015: 839875.

5. Dilawari JB, Bambery P, Chawla Y et al. (1994) Hepatic outflow obstruction (Budd-Chiari syndrome): experience with 177 patients and a review of the literature. Medicine 73(1): 21-36.

6. Kavanagh PM, Roberts J, Gibney R, Malone D, Hegarty J, et al. (2004) Acute Budd-Chiari syndrome with liver failure: the experience of a policy of initial interventional radiological treatment using transjugular intrahepatic portosystemic shunt. J Gastroenterol Hepatol 19(10): 1135-1139.

7. Amarapurkar DN, Punamiya SJ, Patel ND (2008) Changing spectrum of Budd-Chiari syndrome in India with special reference to non-surgical treatment. World J Gastroenterol 14(2): 278-285.

8. Aabha N, Marar S, Nagral S (2010) Anticoagulation and Budd-Chiari syndrome." Indian Journal of Gastroenterology 29(4): 169-169.

9. Wigle P, Hein B, Bloomfield HE, Tubb M, Doherty M (2013) Updated guidelines on outpatient anticoagulation. Am Fam Physician 87(8): 556-566.

10. Bates SM, Greer IA, Middeldorp S, Veenstra DL, Prabulos A-M, et al (2012) VTE, Thrombophilia, Antithrombotic Therapy, and Pregnancy: Antithrombotic Therapy and Prevention of Thrombosis, 9th ed: American College of Chest Physicians Evidence-Based Clinical Practice Guidelines. Chest 141(2 Suppl): e691S-e736S.
11. Abadi S, Einarson A, Koren G (2002) Use of warfarin during pregnancy. Canadian Family Physician 48: 695-697.

12. Savage C, Patel J, Lepe MR, Lazarre CH, Rees CR (2007) Transjugular intrahepatic portosystemic shunt creation for recurrent gastrointestinal bleeding during pregnancy. J VascInterv Radiol 18(7): 902-904.

13. Ingraham CR, Padia SA, Johnson GE, Easterling TR, Liou IW, et al. (2015) Transjugular Intrahepatic Portosystemic Shunt Placement During Pregnancy: A Case Series of Five Patients. Cardiovasc Intervent Radiol 38(5): 1205-1210.

14. Shaheen AA, Myers RP (2010) The outcomes of pregnancy in patients with cirrhosis: a population-based study. Liver Int 30(2): 275-283.

15. Shekhar S, Diddi G (2015) Liver disease in pregnancy, Taiwanese Journal of Obstetrics and Gynecology 54(5): 475

16. Bacak SJ, Loralei L (2015) Thornburg, Liver Failure in Pregnancy. Critical Care Clinics.

17. Licata A, Ingrassia D, Serruto A, Soresi M, Giannitrapani L, et al. (2015) Clinical course and management of acute and chronic viral hepatitis during pregnancy. Journal of Viral Hepatitis 22(6): 515-523.

18. Rasheed SM, Abdel Monem AM, Abd Ellah AH, Abdel Fattah MS (2013) Prognosis and determinants of pregnancy outcome among patients with post-hepatitis liver cirrhosis. International Journal of Gynecology\& 121(3): 247-251.

\section{Your next submission with Juniper Publishers will reach you the below assets}

- Quality Editorial service

- Swift Peer Review

- Reprints availability

- E-prints Service

- Manuscript Podcast for convenient understanding

- Global attainment for your research

- Manuscript accessibility in different formats

( Pdf, E-pub, Full Text, Audio)

- Unceasing customer service

Track the below URL for one-step submission https://juniperpublishers.com/online-submission.php 